\title{
Farklı Mısır (Zea mays L.) Alt Türlerinin Körpe Mısır Özelliklerinin Karşılaştırılması
}

\author{
Burhan Kara* Ahmet Gündüz Cengiz Işık Aykut Şener
}

Süleyman Demirel Üniversitesi, Ziraat Fakültesi, Tarla Bitkileri Bölümü, Isparta

Geliş tarihi (Received): 15.09.2017Kabul tarihi (Accepted): 17.10.2017

\begin{abstract}
Anahtar kelimeler:
Özet. Araştırma; farklı mısır alt türlerinin (atdişi, sert, cin ve şeker mısır) körpe koçan verimi,

Körpe mısır, Zea mays, bazı körpe koçan özellikleri ve tane mineral besin içeriklerini karşıaştırmak amacıyla 2016 mineral besin, verim ve 2017 yıllarında Isparta koşullarında yürütülmüştür. Deneme; "Bora" (atdişi mısır), "Karadeniz yıldızı" (sert mısır), "Ant Cin-98" (cin mısır) ve "BATEM tatı" (şeker mısır) mısır çeşitleri kullanılarak Tesadüf Blokları Deneme Desenine göre 3 tekerrürlü olarak yürütülmüştür. Her çeşide ait körpe mısırlar, koçan püskülünün çıkışından itibaren 3. günde hasat edilmiştir. Mısır alt türlerinin körpe koçan boyu, çapı (ikinci yıl hariç) ve verimleri arasındaki farklar istatistiksel olarak önemli olmuştur. İncelenen karakterleri bakımından atdişi mısır çeşidinin körpe koçan özellikleri diğer mısır alt türlerinden daha yüksek olmuştur. Onu sert mııır, şeker mısır ve cin mısır takip etmiştir. 2016 yılında körpe koçan boyları,

*Sorumlu yazar burhankara@sdu.edu.tr çapları ve körpe koçan verimleri sırasıyla $9.10-11.80 \mathrm{~cm}, 10.10-14.40 \mathrm{~mm}$ ve $128.00-155.20$ $\mathrm{kg} \mathrm{da}^{-1}$, bu özellikler 2017 yılında sırasıyla, $9.56-12.16 \mathrm{~cm}, 13.66-14.93 \mathrm{~mm}$ ve 118.40-164.76 $\mathrm{kg} \mathrm{da}^{-1}$ arasında değişmiştir. Mısır alt türlerinin mineral besin içerikleri arasındaki farklar istatistiksel olarak önemli olmamıştır.
\end{abstract}

\section{Comparison of Baby Corn Characteristics of Different Corn (Zea mays L.) Subspecies}

\section{Keywords:}

Baby corn, Zea mays,

mineral nutrition, yield

\begin{abstract}
The research was carried out with aim to compare on baby corn yield, some baby corn characteristics and seed mineral nutrient contents of different corn subspecies (dent corn, flint corn, popcorn and sweet corn) in Isparta conditions in 2016 and 2017 years. The experiment was set up according to a Randomized Complete Block Design with three replicates using the "Bora" $F_{1}$ dent corn, "Karadeniz yıldızı" (flint corn), "Ant Cin-98" (popcorn) and "BATEM tatlı" $F_{1}$ sweet corn cultivars. According to cultivars, baby corns were harvested in $3^{\text {rd }}$ day from ear silk-out time. The differently between baby corn length, diameter (except for second year) and yields were statistically significant. In tem of examined characteristics, baby corn traits of dent corn were higher than the other corn subspecies. The flint corn, sweet corn and popcorn followed it. Baby corn length, diameter and baby corn yield were varied between $9.10-11.80 \mathrm{~cm}, 10.10-14.40 \mathrm{~mm}$ and $128.00-155.20 \mathrm{~kg} \mathrm{da}^{-1}$ respectively, in 2016 year, these characteristics was varied between $9.56-12.16 \mathrm{~cm}, 13.66-14.93 \mathrm{~mm}$ and 118.40-164.76 $\mathrm{kg} \mathrm{da}^{-1}$ respectively, in 2017 year. The differently between mineral nutrient contents of maize subspecies weren't statistically significant.
\end{abstract}




\section{Giriş}

Körpe mısır; koçan püskülü çıkarma devresinde döllenmemiş yumurtalıklar topluluğu olarak adlandırımaktadır (Galinat 1985). Körpe mısır yetiştiriciliğinde; şeker mısır, at dişi ve sert mısır kullanılabilir. Fakat şeker mısır daha erkenci olması, kardeşlenme özelliğinin olması, kısa boylu olduğu için elle hasadının daha kolay olmasından dolayı tercih edilmektedir. Şeker mısır tohumluğunun pahalı olması ise dezavantajıdır. Hibrit çeşitler sentetik ve açıkta tozlanan çeşitlere göre önemli ölçüde yüksek verim vermektedir. Ayrıca hibrit çeşitlerin üniform körpe mısır koçan boyu, çapı, bitki boyu, çiçeklenme, koçan püskülü çıkarma ve olgunlaşmasından dolayı avantajları vardır. Yağışı ıölgelerde ise açıkta tozlanan çeşitler olumsuz koşullara daha dayanıklı olmalarından dolayı üreticiler tarafında tercih edilmektedir (Anonim 2014a).

Dünyada en fazla körpe mısır üretici ülkeler, Tayland, Sri Lanka, Çin, Tayvan, Zambiya, Güney Afrika, Kostarika, Guetelama ve Honduras'tır. En fazla tüketici ülkeler ise İngiltere, ABD, Hollanda, Kanada, Almanya, Malezya, Tayvan, Japonya ve Avustralya'dır. Körpe mısır üretimi ilk olarak 1976 yılında Tayland'da başlamıştır ve dünyada en fazla körpe mısır üreten ülkelerin başında gelmektedir. Tayland'da taze, dondurulmuş ve konserve körpe misır, en fazla tüketilen popüler sebzeler arasındadır. 2004 yılında 34 858 ha alanda 249303 ton körpe mısır üretilmiş, bunun \%61.0'i iç tüketimde kullanılmış, kalan \%39.0'unu ise ihraç etmişlerdir. Tayland her yıl yaklaşık 25 milyon dolar körpe mısır ihracatından gelir elde etmektedir. Dünya körpe mısır ticaretinin yaklaşık \%80'ni tek başına Tayland tarafından yapılmaktadır ve yaklaşık 30 ülkeye körpe mısır, 100 ülkeye ise tatı mısır ihracatı gerçekleştirmektedirler. Avrupa ülkeleri intiyaçlarını Uzakdoğu ülkelerinden özellikle Tayland'dan karşılamaktadırlar (Anonim 2014b). Türkiye'de son yıllarda büyük marketlerde ve turistik bölgelerde körpe mısır tüketimi giderek yaygınlaşmaktadır. Ülkemizde henüz çok az bilinmekle birlikte bu ürünün tanınması ve üretilmesi ile daha yakın olan Avrupa ülkelerine ihraç edilerek ekonomik gelir elde dilebilir. Hooda and Kawatra (2013) körpe mısırın \%90.03 nem, \%17.96 protein, \%2.13 yağ, \%5.3

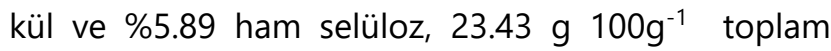
çözülebilir şeker, $1.96 \mathrm{~g}_{100 \mathrm{~g}^{-1}}$ indirgenmiş şeker, $95.00 \mathrm{mg} 100 \mathrm{~g}^{-1}$ kalsiyum, $345.0 \mathrm{mg} 100 \mathrm{~g}^{-1}$ magnezyum, $898.62 \mathrm{mg} 100 \mathrm{~g}^{-1}$ fosfor içerdiğini belirtmişlerdir.

Araştırma farklı mısır alttürlerinin (atdişi, sert, cin ve şeker mısır) körpe mısır koçan özellikleri, körpe koçan verimi ve mineral besin içerikleri karşılaştırmak amacıyla yürütülmüştür.

\section{MATERYAL VE METOD}

Araştırma Süleyman Demirel Üniversitesi Ziraat Fakültesi Araştırma ve Uygulama arazisinde 2016 ve 2017 yıllarında, Bora (atdişi mısır), BATEM tatlı (şeker mısır), Karadeniz yıldızı (sert mısır) ve Ant Cin-98 (cin mısır) mısır çeşitleri kullanılarak Tesadüf Blokları Deneme Desenine göre 3 tekerrürlü olarak yürütülmüştür. Bora, Karadeniz yıldızı ve Ant Cin-98 çeşitleri bölgede yapılan araştırmalar sonucunda genel olarak yüksek verimli oldukları için, BATEM tatlı çeşidi ise kardeşlenme özelliği yüksek olduğu için tercih edilmiştir.

Denemenin yürütüldüğü 2016 ve 2017 yıllarında Nisan-Temmuz aylarına ilişkin toplam yağıs miktarı sırasıyla $173.5 \mathrm{~mm}$ ve $219.1 \mathrm{~mm}$, uzun yıllar ortalaması ise $154.2 \mathrm{~mm}$ olarak gerçekleşmiştir. Aynı döneme ait ortalama sıcaklık 2016 ve 2017 yıllarında, sırasıyla 21.0 ve $17.7^{\circ} \mathrm{C}$ olup uzun yıllar sıcaklık ortalamasından $\left(17.2^{\circ} \mathrm{C}\right.$ ) yüksek olmuştur (Çizelge 1$)$.

Deneme alanı killi-tınlı bir yapıya sahip olup, hafif bazik (pH: 8.1), kireç oranı yüksek (\%30.1) ve organik madde oranı düşük (\%1.8) yapıdadır.

Deneme toprağı kulaklı pullukla $20 \mathrm{~cm}$ derinliğinde sürülmüş, ekimden önce diskaro çekilerek tohum yatağı hazırlanmış ve her iki yılda da Mayıs aynının ilk haftasında kurulmuştur. Parsel sıra uzunluğu $6 \mathrm{~m}$ ve 6 sıra olarak düzenlenmiş, bloklar arasında $2 \mathrm{~m}$, her parsel arasında $1 \mathrm{~m}$ aralık bırakılmış ve ekimden önce parsellere markör çekilecek ve $70 \mathrm{~cm}$ sıra arası ve 16 $\mathrm{cm}$ sıra üzeri mesafede $(70 \mathrm{~cm} \times 16 \mathrm{~cm})$, her ocağa iki tohum gelecek şekilde $3-4 \mathrm{~cm}$ derinliğe elle ekilmiştir. Çıkıştan sonra her ocakta bir bitki kalacak şekilde tekleme yapılmıştır. Dekara $15 \mathrm{~kg}$ azotun $1 / 3$ ekimle, kalan 2/3 bitki $35-40 \mathrm{~cm}$ boylandığı dönemde amonyum sülfat formunda (\%21), $5 \mathrm{~kg} \mathrm{da}^{-1}$ saf fosfor tamamı ekimle birlikte triple süper fosfat formunda (\%43-46 $\mathrm{P}_{2} \mathrm{O}_{5}$ ) uygulanmıştır (Can ve Akman, 2014). Deneme, damlama sulama sistemi ile sulanmış ve diğer standart bakım işlemleri yapılmıştır.

Hasat; çeşitlerin çiçeklenme sürelerine göre birinci yıl 25 Haziran-9 Temmuz 2016, ikinci yıl 26 Haziran-12 Temmuz 2017 tarihlerinde yapılmıştır. Koçan püskülü çıkışından itibaren 3. günde hasat edilen körpe mısırda, Bar-Zur ve Saadi (1990)'nin yöntemlerine göre körpe mısır boyu $(\mathrm{cm})$, körpe mısır çapı $(\mathrm{mm})$ ve körpe mısır verimi $\left(\mathrm{kg} \mathrm{da}^{-1}\right)$ ölçülmüştür. Her çeşidin körpe koçanlarında $\mathrm{Fe}, \mathrm{Ca}$, $\mathrm{Cu}$, Mg ve $\mathrm{Zn}$ Atomik Absorbsiyon Spektrofotometresi, N yarı makro Kjeldahl, K 
Çizelge 1. Deneme alanı ve yıllarına ait iklim verileri*.

Table 1. Climatic data belong to experiment area and years.

\begin{tabular}{ccccccc}
\hline \multirow{2}{*}{$\begin{array}{c}\text { iklim } \\
\text { faktörleri }\end{array}$} & Yıllar & Nisan & Mayıs & Haziran & Temmuz & $\begin{array}{c}\text { Toplam/ } \\
\text { Ortalama }\end{array}$ \\
\cline { 2 - 6 } & 2016 & 47.8 & 87.6 & 12.4 & 25.7 & 173.5 \\
Yağış & 2017 & 25.6 & 149.5 & 30.9 & 13.1 & 219.1 \\
$(\mathrm{~mm})$ & Uzun yıllar & 56.6 & 50.8 & 28.4 & 18.4 & 154.2 \\
\hline Ortalama & 2016 & 14.5 & 20.1 & 24.0 & 25.4 & 21.0 \\
sıcaklık & 2017 & 10.6 & 14.9 & 20.1 & 25.0 & 17.7 \\
$\left({ }^{\circ} \mathrm{C}\right)$ & Uzun yıllar & 10.8 & 15.6 & 20.1 & 22.3 & 17.2 \\
\hline
\end{tabular}

*iklim verileri Isparta meteoroloji istasyonundan alınmıştır.

Fleymfotometrik yöntemiyle ve $P$ molibdovanadofosforik asit metoduna göre belirlenmiştir (Kacar ve Inal 2013).

Elde edilen veriler, SAS 5.1 istatistik paket programından faydalanılarak tesadüf bloklarında faktöriyel deneme desenine göre varyans analizleri yapılmış ve ortalamalar arasındaki farklılıklar LSD testine göre karşılaştırılmıştır (Steel and Torrie 1980).

\section{BULGULAR VE TARTIŞMA}

Mısır çeşitlerinin incelenen körpe mısır koçan özellikleri bakımından yıllar arasında istatistiksel olarak fark çıkmamıştır. Körpe mısır amaçlı üretilen mısır alt türleri ekimden itibaren birinci yıl 52-67 gün, ikinci yıl 53-70 gün gibi kısa bir sürede hasat edilmesi ve sulanan bir bitki olması nedeniyle iklimsel faktörlerden etkilemediği ve bu nedenle yılların ortalamaları birbirine yakın olduğu düşünülmektedir.

Mısır alt türlerinin körpe mısır koçan boyu, çapı ve verimleri arasında farklar (ikinci yılın koçan çapı hariç) istatistiksel olarak her iki yılda da önemli olmuştur. Mısır alt türlerinin 2016 yılında körpe koçan boyları 9.10-11.80 cm, körpe koçan çapları 10.10-14.40 mm ve körpe koçan verimleri 128.00-155.20 kg da-1, bu özellikler 2017 yılında sırasıyla, 9.56-12.16 cm, 13.66$14.93 \mathrm{~mm}$ ve $118.40-164.76 \mathrm{~kg} \mathrm{da}{ }^{-1}$ arasında değişmiştir. İncelene özelliklerin en yüksek değerleri atdişi mısır çeşidinde ölçülürken, genel olarak en düşük değerler ise cin mısırda ölçülmüştür (Çizelge 2). Araştırmada kullanılan mısır çeşitlerinin bitki ve koçan özellikleri bakımından büyükten küçüğe doğru atdişi, sert, şeker ve cin mısır olarak sıralanabilir. Bu özellikler genetik farklılık olup, körpe koçanda da kendini gösterdiği düşünülmektedir. Körpe mısırın koçan verimi ve koçan özellikleri çeşit özelliğine, morfolojik yapılarına, erkenci ve geççi olmalarına, koçan bağlama sayısı gibi özeliklerine bağlı olarak önemli ölçüde değişmektedir. Körpe mısır koçan özellikleri üzerine yapılan önceki çalışmalarda; Almeida et al. (2005) ortalama körpe mısır koçan çapı $13.6 \mathrm{~mm}$ boyu 9.36 $\mathrm{cm}$ ve koçan sayısı 6814.6 adet $\mathrm{da}^{-1}$ olduğunu, Gözübenli ve Konuşkan (2009) farklı mısır çeşitlerinde ortalama körpe koçan verimlerinin 208.3-276.5 kg da1 arasında değiştiğini ve Castro et al. (2013) ortalama körpe mısır koçan çapının 16.5 mm, koçan boyu 11.4 $\mathrm{cm}$ ve verimin ise $599.0 \mathrm{~kg} \mathrm{da}{ }^{-1}$ olarak tespit etmişlerdir.

Çizelge 2. Farklı mısır alt türlerinin körpe koçan hasat zamanları, boyu, çapı ve verim ortalamaları. Table 2. Baby corn harvest times, length, diameter and yields averages of different maize subspecies.

\begin{tabular}{|c|c|c|c|c|c|c|c|c|}
\hline \multirow{2}{*}{$\begin{array}{l}\text { Mısır alt türleri } \\
\text { (Çeşitler) }\end{array}$} & \multicolumn{2}{|c|}{$\begin{array}{l}\text { Hasat tarihleri } \\
\text { (gün) }\end{array}$} & \multicolumn{2}{|c|}{$\begin{array}{l}\text { Körpe koçan boyu } \\
(\mathrm{cm})\end{array}$} & \multicolumn{2}{|c|}{$\begin{array}{c}\text { Körpe koçan çapı } \\
\text { (mm) }\end{array}$} & \multicolumn{2}{|c|}{$\begin{array}{c}\text { Körpe koçan verimi } \\
\left(\mathbf{k g ~ d a}^{-1}\right)\end{array}$} \\
\hline & 2016 & 2017 & 2016 & 2017 & 2016 & 2017 & 2016 & 2017 \\
\hline Atdişi mısır (Bora) & 67 & 70 & $11.80 \mathrm{a}$ & $12.16 \mathrm{a}$ & $14.40 \mathrm{a}$ & 14.93 & $155.20 \mathrm{a}$ & $164.76 \mathrm{a}$ \\
\hline Sert mısır (K. Yıldızı) & 63 & 66 & $10.42 a b$ & $11.96 \mathrm{a}$ & $13.56 \mathrm{a}$ & 14.60 & 148.00 a & $131.53 \mathrm{bc}$ \\
\hline Cin misır (AntCin-98) & 58 & 60 & $9.10 \mathrm{~b}$ & $9.56 b$ & $10.10 \mathrm{~b}$ & 13.66 & $128.00 \mathrm{~b}$ & $118.40 \mathrm{c}$ \\
\hline Şeker mısır (B. Tatlı) & 52 & 53 & $9.48 \mathrm{~b}$ & $11.10 \mathrm{a}$ & $12.73 a b$ & 14.23 & $140.06 \mathrm{ab}$ & $148.16 \mathrm{ab}$ \\
\hline Yıl ortalama & & & $10.20^{\text {öd }}$ & 11.19 & 12.69 öd & 14.35 & $142.81^{\text {öd }}$ & 140.71 \\
\hline Kareler ortalaması & & & 4.4422 & 4.2000 & 10.4022 & 0.883 & 172.111 & 810.272 \\
\hline F değeri & & & $16.59 * \star$ & $5.30 *$ & $9.37^{\star}$ & 0.77 & $6.83^{*}$ & $12.63^{* *}$ \\
\hline Lsd (\%) & & & 1.566 & 1.764 & 3.188 & ö.d & 15.194 & 24.249 \\
\hline V.K (\%) & & & 4.61 & 8.15 & 6.70 & 7.44 & 3.37 & 5.79 \\
\hline
\end{tabular}

*: $\mathrm{P} \leq 0.05, * *: \mathrm{P} \leq 0.01$ düzeyinde önemli, öd: Önemli değil. 
Çalışımızda elde edilen körpe koçan özellikleri araştırmalarda belirtilen sınırlar içerisinde yer almıştır. Kasikranan ve ark. (2001) körpe mısır verim ve koçan özelikleri cinslere ve hatta aynı cinse ait mısır çeşitler arasında farklılıklar gösterdiğini bildirmişlerdir. Körpe koçan verim ve özelliklerinin çeşitlere göre değiştiğini Izhar and Chakraborty (2014), Castro et al. (2013) ve Lopes et al. (2016) tarafından da rapor edilmiştir.

Atdişi, sert, cin ve şeker mısır çeşitlerinin incelenen körpe mısır mineral besin içerikleri arasında istatistiksel olarak fark ortaya çıkmamıştır. Mısır çeşitlerinin $\mathrm{N}, \mathrm{P}, \mathrm{K}, \mathrm{Ca}, \mathrm{Mg}, \mathrm{Fe}, \mathrm{Cu}$ ve $\mathrm{Zn}$ içerikleri, sirasiyla \%2.41-2.89, \%0.340-0.368, \%1.15-1.33, $\% 0.205-0.225, \% 0.129-0.136,25.93-27.68$ ppm, 6.32$7.42 \mathrm{ppm}$ ve 19.12-22.63 ppm arasında değişmiştir.
Incelenen bu özelliklerin en yüksek ve en düşük değerleri çeşitlere göre farklılık göstermiştir (Çizelge 3). Genel olarak, körpe mısır koçan püskülünün çıkısıından 2-3 gün sonra hasat edilmektedir. Bu dönmede besin maddelerinin koçana taşınma işlemi minimum düzeydedir. Ancak az da olsa şeker mısırın diğer mısır alt türlerine göre daha yüksek mineral besin madde içerdiği söylenebilir. Coşkun ve ark. (2006) genel olarak şeker mısır bileşim bakımından diğer mısır alttürlerinden daha yüksek besin maddesine içerdiğini, Izhar and Chakraborty (2014) şeker mısırın potasyum içeriğinin yüksek olduğunu rapor etmişlerdir. Wang (2009) ve Moreira et al. (2010) körpe mısır besin element içerikleri çeşitlere göre değiştiğini bildirmişlerdir.

Çizelge 3. Farklı mısır alt türlerinin mineral besin içerikleri ${ }^{+}$.

Table 3. Mineral nutrient contents of different maize subspecies.

\begin{tabular}{|c|c|c|c|c|}
\hline \multirow[t]{2}{*}{ Mısır alt türleri (Çeşitler) } & \multicolumn{4}{|c|}{ Mineral besin içerikleri } \\
\hline & N (\%) & $\mathbf{P}(\%)$ & K (\%) & $\mathrm{Ca}(\%)$ \\
\hline Atdişi mısır (Bora) & 2.65 & 0.359 & 1.26 & 0.214 \\
\hline Sert mısır (K. Yıldızı) & 2.63 & 0.343 & 1.28 & 0.205 \\
\hline Cin mısır (AntCin-98) & 2.41 & 0.340 & 1.15 & 0.215 \\
\hline Şeker mısır (B. Tatı) & 2.89 & 0.368 & 1.33 & 0.225 \\
\hline Kareler ortalaması & 0.1123 & 0.0005 & 0.0107 & 0.0002 \\
\hline F değeri & 2.57 & 2.72 & 1.31 & 1.10 \\
\hline Lsd (\%) & ö.d & ö.d & ö.d & ö.d \\
\hline \multirow[t]{2}{*}{ V.K (\%) } & 7.99 & 3.89 & 7.27 & 6.26 \\
\hline & $\mathrm{Mg}(\%)$ & $\mathrm{Fe}(\mathrm{ppm})$ & $\mathrm{Cu}(\mathrm{ppm})$ & Zn (ppm) \\
\hline Atdişi mısır (Bora) & 0.129 & 25.93 & 7.38 & 20.56 \\
\hline Sert mısır (K. Yıldızı) & 0.133 & 26.94 & 7.30 & 22.63 \\
\hline Cin misır (AntCin-98) & 0.132 & 26.72 & 6.32 & 21.24 \\
\hline Şeker mısır (B. Tatlı) & 0.136 & 27.68 & 7.42 & 19.12 \\
\hline Kareler ortalaması & 0.0001 & 12.731 & 1.9557 & 6.3780 \\
\hline F değeri & 0.10 & 4.56 & 3.92 & 5.100 \\
\hline Lsd (\%) & ö.d & ö.d & ö.d & ö.d \\
\hline V.K (\%) & 7.92 & 1.76 & 5.80 & 6.06 \\
\hline
\end{tabular}

$+:$ Mineral besin içerik değerleri çalışmanın birinci (2016) yılına aittir.

*: $P \leq 0.05, * *: P \leq 0.01$ düzeyinde önemli, öd: önemli değil.

\section{SONUÇ}

Araştırma sonuçlarına göre, körpe koçan boyu, çapı ve verim bakımından atdişi mısır daha yüksek değerlere sahip olurken, onu sert mısır, şeker mısır ve cin mısır izlemiştir. Körpe mısır mineral besin içerikleri arasında ise mısır alt türleri arasında istatistiksel olarak fark ortaya çıkmamıştır.

Sonuç olarak, körpe koçan boyu, verimi ve mineral besin içerikleri göz önüne alındığında kullanılan tüm çeşitlerin körpe mısır olarak yetiştirilebileceği, ticari olarak daha yüksek verim ve koçan özelliklerinden dolayı; atdişi mısır, sert mısır, şeker mısır ve cin mısır sıralamasıyla önerilebilir.

\section{TEŞEKKÜR}

Bu çalışmanın birinci yılı TÜBiTAK 2209/A Üniversite Öğrencileri Yurt İçi Araştırma Projeleri Destek Program' tarafından desteklenmiştir. Desteklerinden dolayı TÜBITAK'a teşekkür ederiz.

\section{KAYNAKLAR}

Almeida IPC., Silva PSL., Negreiros MZ and Barbosa Z., 2005. Baby corn, green ear, and grain yield of corn cultivars. Horticulture Brasilia, 23: 960-964.

Anonim 2014a. Baby corn. http://www.uky.edu/Ag/CCD /introsheets/babycorn.pdf [Erişim tarihi: 9 Haziran 2014]. 
Anonim, 2014b. Baby corn production, processing and marketing in Thailand. Report Submitted to Field Fresh Foods Pvt. Ltd., Gurgaon, India. http://www.volkerkleinhenz.com/publications/babycorn-production-processing-and-marketing-in-thailand [Erişim tarihi: 11 Haziran 2014].

Bar-Zur A and Saadi H., 1990. Prolific maize hybrids for baby corn. Journal of Horticulture Science, 65: 97-100.

Can M ve Akman Z., 2014. Uşak ekolojik şartlarında farklı azot dozlarının şeker mısırın (Zea mays saccharata Sturt.) verim ve kalite özelliklerine etkisi. Süleyman Demirel Üniversitesi Ziraat Fakültesi Dergisi, 9: 93-101.

Castro RS., Silva PSL and Cardoso MJ., 2013. Baby corn, green corn, and dry corn yield of corn cultivars. Horticultura Brasileira, 31: 100-105.

Coşkun, MB, Yalçın I and Özarslan C., 2006. Physical properties of sweet corn (Zea mays saccharata Sturt.). Journal Food Enginering, 74: 523-528.

Galinat WC., 1985. Whole Ear Baby Corn, A New Way to Eat Corn. Proc. Northeast Corn Improv. Conference, 40: 22 27.

Gözübenli H ve Konuşkan Ö., 2009. Farklı Bitki Sıklıklarının Bazı Mısır Genotiplerinde Körpe Koçan (baby corn) Verimi ve Özelliklerine Etkisi. Türkiye VIII. Tarla Bitkileri Kongresi, Poster Bildiriler, 19-22 Ekim, Hatay.

Hooda S and Kawatra A., 2013. Nutritional evaluation of baby corn (Zea mays L.). Nutrition and Food Science, 4: 68-73.
Izhar T and Chakraborty M., 2014. Genetic analysis of maize (Zea mays L.) genotypes for baby corn, green ear and grain yield. Maize Genomics and Genetics, 5: 1-6.

Kacar B ve İnal A. 2013. Bitki Analizleri, Nobel Yayıncılık, Ankara.

Kasikranan S., Jones H and Suksri A., 2001. Growth, yield, qualities and appropriate sizes of eight baby corn cultivars (Zea mays L.) for industrial uses grown on oxic paleustults soil, Northeast Thailand. Pakistan Journal of Biological Sciences, 4: 32-36.

Lopes AP., Nobrega LHP., Pacheco FP and Cruz-Silva CTA., 2016. Maize varieties for baby corn yield and postharvest quality under organic cropping. Bioscience Journal, 32: 298-307.

Moreira JN., Silva PSL., Silva KMB., Dombroski JLD and Castro RS., 2010. Effect of detasseling on baby corn, green ear and grain yield of two maize hybrids. Horticulture Brasília, 28: 406-411.

Steel RGD and Torrie JH., 1980. Principles and Procedures of Statistics. McGraw-Hill Book Company, Inc., New York, USA.

Wang Z., 2009. Effect of different schedules of baby corn (Zea mays L.) harvests on baby corn yield, grain yield, and economic profit value. Western Kentucky University, Masters Theses \& Specialist Project. 